\title{
The Impact of Outside Pressure on Saudi University Students Decision Making
}

\author{
Mamoon Muhsin Alaraj \\ Academic Language Support Unit \\ Faculty of Engineering \\ King Abdulaziz University \\ P. O. Box 80204, Jeddah 21589, KSA \\ Yousof Qaed Alotaibi \\ Electrical and Computer Engineering \\ Faculty of Engineering \\ King Abdulaziz University \\ P. O. Box 80204, Jeddah 21589, KSA
}

\begin{abstract}
This study aimed to seek a deep understanding of the impact of outside pressure on Saudi university students and how this pressure affected their decision making. The data collection tool was a 15-item survey that was distributed amongst King Abdulaziz University students which resulted in a sample of 110 students. The results indicated that societal pressure was the main pressure that steered students' decisions and that this adversely affected students' psyche and mental health first, and their passion and drive second. These results agreed with prior studies, especially the results concerned with the mental health of students and their social economic status. Suggestions for recommended solutions were as follows: having psychological and academic advisors in campus to help students with their stress and pressure in their personal and academic lives and holding events by universities with the aim of changing societies' pre-conceived notions against certain fields of study.
\end{abstract}

Keywords: Decision Making, Outside Pressure, Stress, University Student

\section{Introduction}

One of the main attributes that set human beings apart from other living things is how much we react to our surroundings and society. And this reaction can have negative repercussions on the livelihood and psyche of the affected. All university students have ambitions and dreams that they follow and do their best to achieve, however most of them wind up deviating from these goals which they were driven to see through and be passionate about. According to (Polavieja and Platt, 2014) as little as 6\% of adults hold the jobs that they aspired to hold as kids. Outside pressure is just one reason, one of many that drastically changes the direction of people in their struggle to flourish and do good. One of the main demographics that suffer from such interferences in their plans is students who are at the verge of making some of the most important life verdicts such as decisions of education and field of study. And depending on the reality enclosing them, poverty for example, they may change their decisions being affected by their families in the immediate time frame, etc. not realizing that these decisions may bring them heartache and sorrow in the future. For that reason, we are conducting this study about the outside pressure that Saudi university students face and how this pressure affects their decision making. The importance of this topic stems from the fact that Saudi Arabia is in a transitional phase and it needs the energy and passion of its young citizens to fulfill this transformation. The shaping of our future falls on the able shoulders of our young men and women, and if they keep heading to fields they aren't really interested in, their talents won't be properly utilized.

To better understand the types of pressure and issues Saudi students face we need to start by looking at the aspects of the problem generally. For example, what are the whole issues students face? What is the consensus and how does it apply to the Saudi demographic? The main obstacle once selecting an occupation is the absence of economic incomes. Several undergraduates, particularly those with inadequate economic incomes have the persistent dread that if they choose a job built on their welfares or desire, they will not have a good career quickly after their studies. This obliges them to pursue a job which they believe will be quicker and safer in terms of job opportunities chances. Individual responsibilities also oblige them to accelerate their job-related choices (Tolosa, 2018). Moreover, outside opinions can raise the awareness of the positive effects of some of the stumbling blocks that students face. 
Every person has desires that align with his/her abilities and qualifications, and to reach these desires there must be outside motives and effects that make this person work constantly to achieve targeted goals (Noor Aldin and Mubarakah, 2016).

Lastly, we need to assess how much of these issues apply to Saudi university students and in what ways this demographic is unique to other nations. we need to mark the bullet points of this study with pinpoint accuracy and establish questions that are both clear and encompassing, so that it may help us arrive at meaningful conclusions. Proceeding from what has been said previously we can state the following questions:

1- What are the types of outside pressure Saudi university students face?

2- What are the important students' decisions that can get affected by these types of outside pressure?

3- How does the outside pressure affect Saudi university students' performance and passion for learning?

\section{Review of Literature:}

This section tries to cover a quick review of previously conducted research work and studies related to pressure and decision-making connection.

First, to what extent do students suffer from pressure? And how does this suffering affect their feelings and behaviors and extend to decision-making? To answer these questions with previously existing literature three various studies are displayed below. First is Pedrelli (2015) which states that joining university could be a worrying period for many undergraduates. Furthermore, to handle academic heaviness, some undergraduates must deal with the demanding responsibilities of parting from their family of origin whereas some may join several family and work duties. In this situation, many undergraduates practice the opening inception of psychological health difficulties. Second is Reilly (2018) which reports that more than $47 \%$ of students seeking counseling suffers from anxiety and $40 \%$ suffers from depression. This information raises two more questions that need review. Firstly, is it only higher-level students who experience pressure? And what are the aftereffects and how prevalent are they? Third, according to Kaur (2013) studying heaviness does not start in university. The anxious failures, fear attacks, breakdowns, and sadness are also apparent in several fresh undergraduates. In relation to the prevalence of the pressure effects a study conducted by (Novotney, 2014) examines data from 125,000 undergraduates from more than 150 universities and colleges. Approximately one-third of U.S. university students has trouble working in the last twelve months due to sadness, and almost half says they feel overwhelming anxiety in the last year. The American College Health Association (2019) also conducts nationally documented research studies intended to help schools in collecting exact information about their students' behaviors, perceptions and health habits. Schools choose the subjects to cover, target population, sample size, survey method and time period. They find that students suffer from a lot of pressure, stress, anxiety, depression and many other mental problems. In other statistics gathered by the Center for Collegiate Mental Health (2017), which is an organization that gathers mental health and stability data from over 263 university and mental health counseling centers, more than $30 \%$ of undergraduates who seek psychological health services state that they have seriously considered suicide (American Psychological Association, 2014).

To conclude, Porcelli and Delgado (2017) found out that avaried series of worrying experiences can impact human choice production in complex ways beyond the simple estimates of a fight-or-flight model. In their study they try to offer vision into this complex contact, possibly in orders that could result in translational applications. And they suggest that pressure experience impacts basic neural circuits involved in learning, processing and making decisions. That says, a considerable array of methodological and theoretical reflections in research on the subject challenge strong cross study contrasts essential for the field to move onward.

\section{Methodology:}

This study aimed to seek a deep understanding of the impact of outside pressure on Saudi students and how it affected their decision making. The chosen data collection tool was a survey since it could allow the students to participate with their experiences which could both show us the extent of the preprocessed options as well as add other options by the respondents not thought of by the questionnaire designer. To come up with a well prepared and strong survey that could cover all research questions and aspects of the issue under investigation, the researchers formed two focus groups and asked them to create the possible items related. Then the proposed survey was given to three experienced specialists for revision and the new draft was piloted on a cohort of 20 students. Finally, considering items' feasibility and validity more modifications and corrections were added and a final version of 15 items was used to collect targeted information. The items utilized were of three types. Firstly, multiple-choice questions were designed to see whether the expected pressure and its effects were truly common or not. Secondly, the linear scale was used solely to measure the agreement level of the respondents with certain statements. 
Lastly, grid type questions were used in one of two ways either letting respondents set a value (i.e. importance) to a variety of choices, or making respondents organize the choices in a certain order (i.e. from least to most important). The survey was distributed amongst King Abdulaziz University students since it is the most diverse and readily available sample of students that we could round the opinions of in such a short time.The survey was answered by 110 respondents with over $90 \%$ of them being in the age demographic between $18 \& 24$. The main problem faced was getting the questions across in the most clear and comprehensive matter. To solve this issue, we resorted to translating the questionnaire into students' native language before distributing it.

\section{Findings:}

The findings of this study were presented under their overarching research questions. There were three research questions (RQs). And for each question, graphs of the main items in the survey that captured the main ideas of that RQ were displayed.

Some results included a thesis status section which aimed to clarify whether the choice was in line with the thesis of the study or not. Others didn't include this section due to difficulty in analyzing the choices.

The first research question was as follows:

RQ1: What are the types of outside pressure Saudi students face?

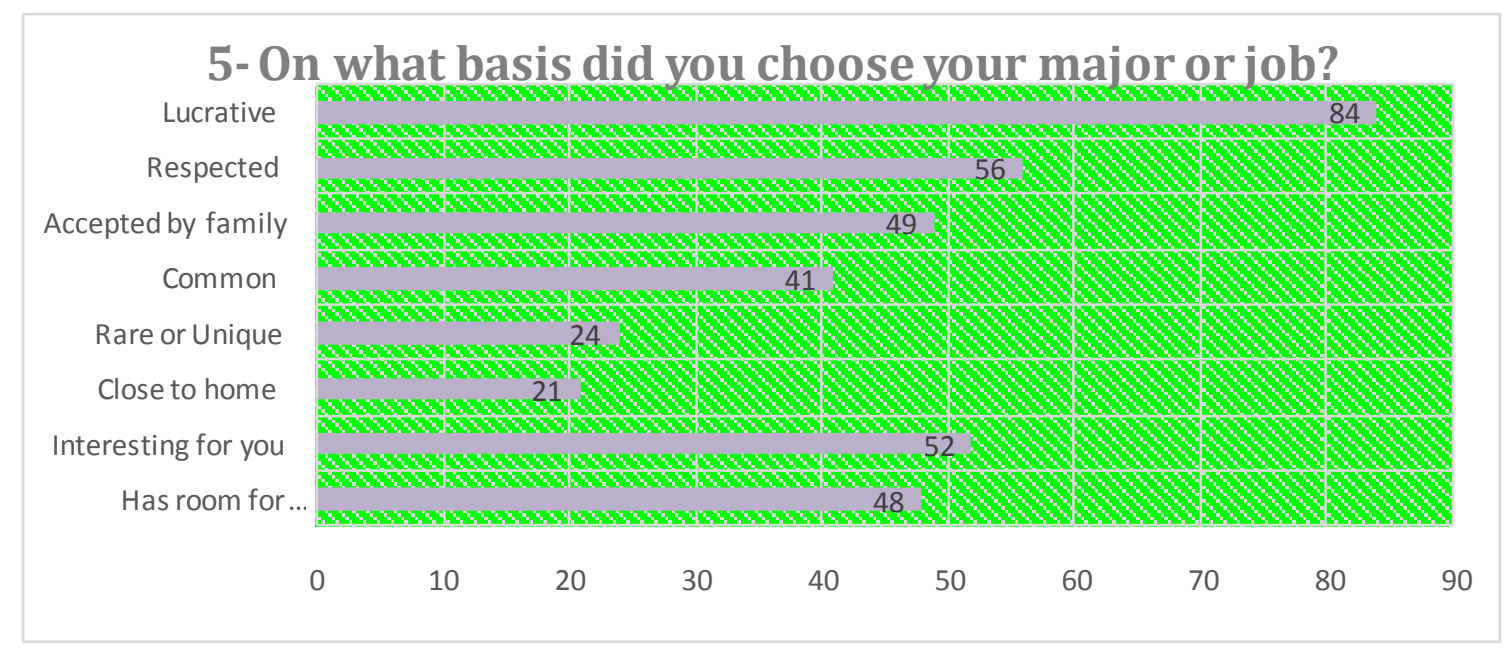

Figure 1: Respondents choices concerning what basis they had for job or major decision making

Aim of the question: to get a better perception of what students base their decisions on As seen in Figure1 the most chosen option was lucrative (monetary), followed by societal respect, then came the interest of the subject (student), after which the middle choices were family acceptance and the room for growth (adaptability). The responses and status of the question were organized in table number 1 below.

Table 1: Results of first graph

\begin{tabular}{|l|l|l|l|}
\hline Choice & Thesis Status & Responses & Percentage \\
\hline Lucrative & Positive & $\mathbf{8 4}$ & $\mathbf{7 6 . 3 6} \%$ \\
\hline Respected & Positive & $\mathbf{5 6}$ & $\mathbf{5 0 . 9 0 \%}$ \\
\hline Accepted by Family & Positive & 49 & $\mathbf{4 4 . 5 4 \%}$ \\
\hline Common & Negative & 41 & $\mathbf{3 7 . 2 7} \%$ \\
\hline Rare or Unique & Negative & $\mathbf{2 4}$ & $\mathbf{2 1 . 8 1 \%}$ \\
\hline Close to Home & Neutral & $\mathbf{2 1}$ & $\mathbf{1 9 . 0 9 \%}$ \\
\hline Interesting for You & Negative & $\mathbf{5 2}$ & $\mathbf{4 7 . 2 7 \%}$ \\
\hline Has Room for Growth & Negative & $\mathbf{4 8}$ & $\mathbf{4 3 . 6 3 \%}$ \\
\hline
\end{tabular}




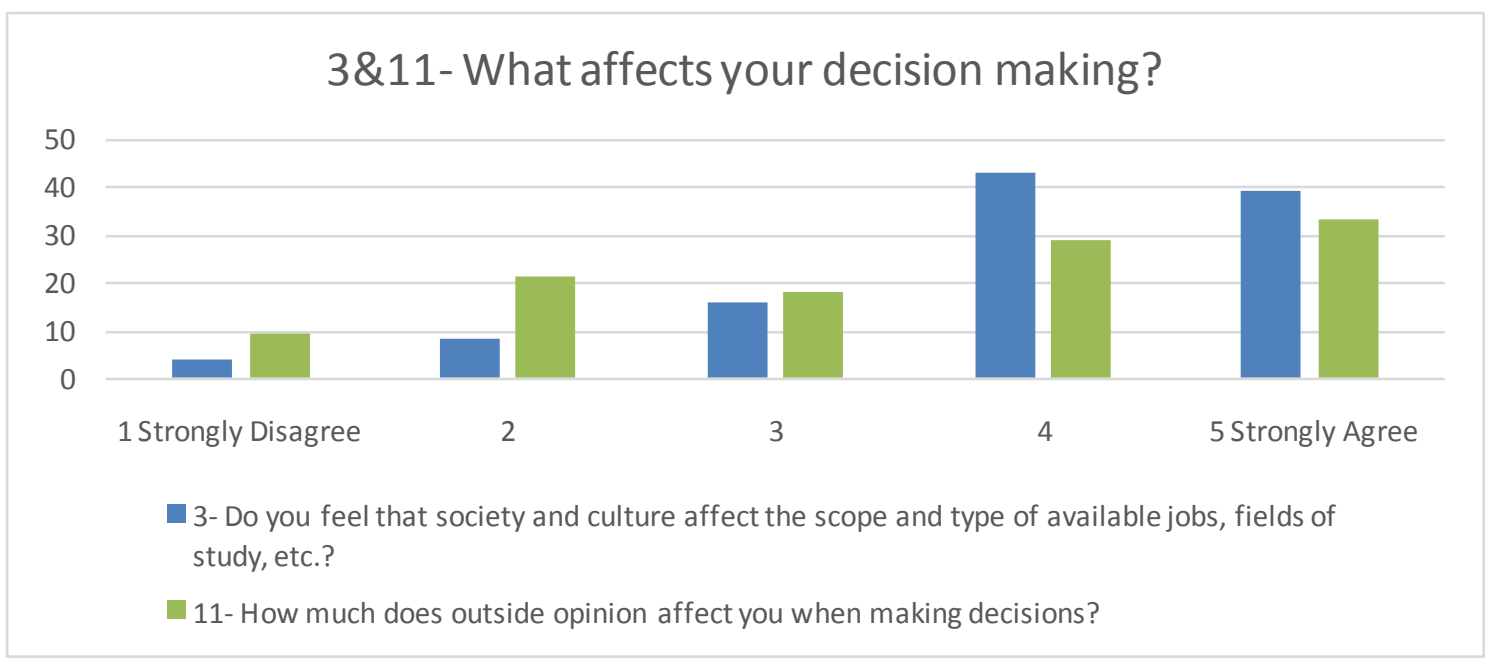

Figure 2: Agreement level with certain statements regarding societal effect on decision making

Aim of the two questions: to find how perceptive the subjects are of the pressure on them

The results for Figure 2 were shown in table 2 below.

Table 2: Results of second graph

\begin{tabular}{|c|c|c|c|c|c|}
\hline Agreement Level & $\begin{array}{c}\text { Responses } \\
\text { for item 3 }\end{array}$ & $\begin{array}{c}\text { Percentage } \\
\text { for item 3 }\end{array}$ & $\begin{array}{c}\text { Responses for } \\
\text { item 11 }\end{array}$ & $\begin{array}{c}\text { Percentages } \\
\text { for item 11 }\end{array}$ & $\begin{array}{c}\text { Thesis } \\
\text { Status }\end{array}$ \\
\hline Strongly disagree & $\mathbf{4}$ & $\mathbf{3 . 6 3} \%$ & $\mathbf{9}$ & $\mathbf{8 . 1 8 \%}$ & Negative \\
\hline Disagree & $\mathbf{8}$ & $\mathbf{7 . 2 7} \%$ & $\mathbf{2 1}$ & $\mathbf{1 9 . 0 9 \%}$ & Negative \\
\hline Neutral & $\mathbf{1 6}$ & $\mathbf{1 4 . 5 4 \%}$ & $\mathbf{1 8}$ & $\mathbf{1 6 . 3 6 \%}$ & Negative \\
\hline Agree & $\mathbf{4 3}$ & $\mathbf{3 9 . 0 9 \%}$ & $\mathbf{2 9}$ & $\mathbf{2 6 . 3 6 \%}$ & Positive \\
\hline Strongly agree & $\mathbf{3 9}$ & $\mathbf{3 5 . 4 5 \%}$ & $\mathbf{3 3}$ & $\mathbf{3 0 \%}$ & Positive \\
\hline
\end{tabular}

The second research question was as follows:

RQ2:What are the important student decisions that can get affected by outside pressure?

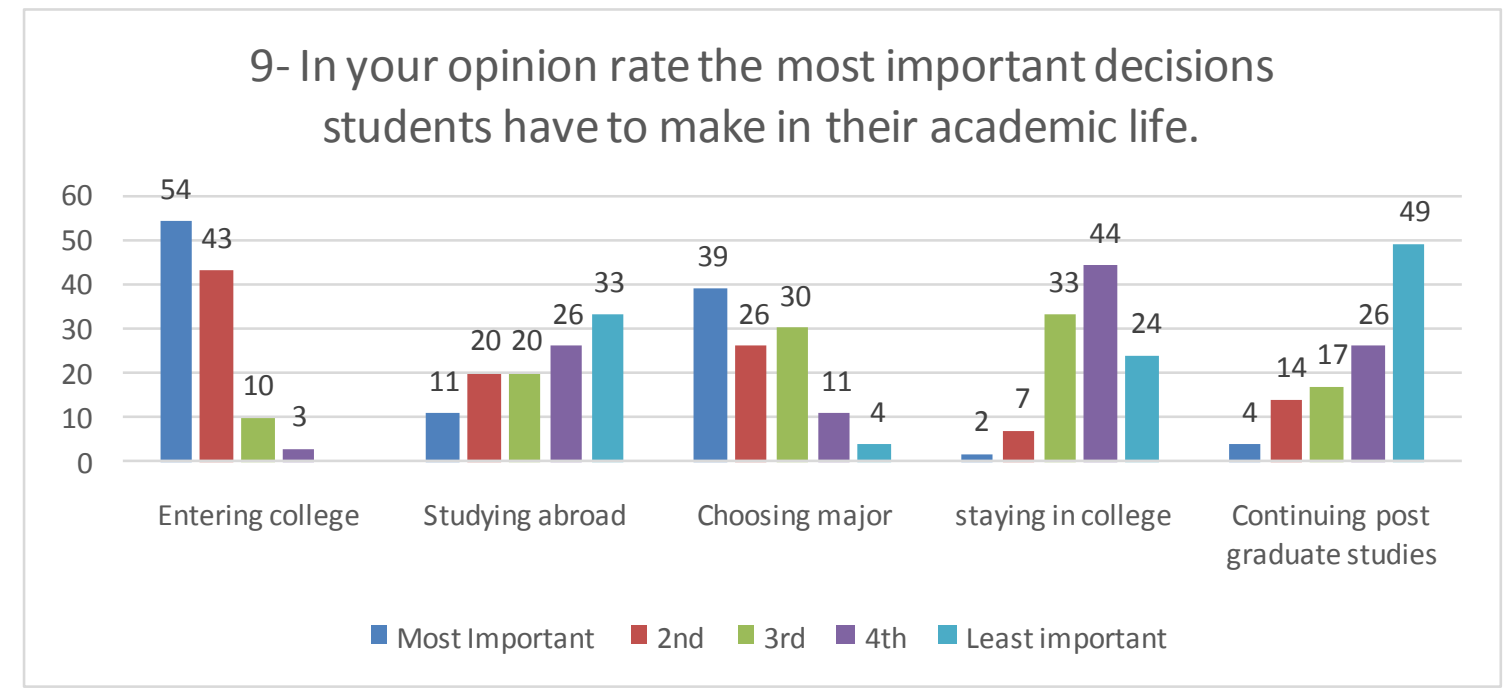

Figure 3: Respondents choices regarding the most important decisions students make

Aim of the question: to get multiple views on which decision is the most important

Respondents chose (entering college) and (choosing major) as the most important while (studying abroad) was the middle choice all around. Other choices (staying in college) and (continuing post graduate studies) were consistently on the lower spectrum. The statistics of this item were broken down in table 3 below. 
Table 3: Results of third graph

\begin{tabular}{|c|c|c|c|c|c|}
\hline Order & $\begin{array}{l}\text { Entering } \\
\text { College }\end{array}$ & $\begin{array}{l}\text { Studying } \\
\text { Abroad }\end{array}$ & $\begin{array}{c}\text { Choosing } \\
\text { Major }\end{array}$ & $\begin{array}{l}\text { Staying in } \\
\text { College }\end{array}$ & $\begin{array}{l}\text { Post Grad. } \\
\text { Studies }\end{array}$ \\
\hline $\begin{array}{c}\text { Most } \\
\text { important }\end{array}$ & $54(49.09 \%)$ & $11(10 \%)$ & $39(35.45 \%)$ & $2(1.81 \%)$ & $4(3.63 \%)$ \\
\hline 2nd & $43(39.09 \%)$ & $20(18.18 \%)$ & $26(23.63 \%)$ & $7(6.36 \%)$ & $14(12.72 \%)$ \\
\hline 3rd & $10(9.09 \%)$ & $20(18.18 \%)$ & $30(27.27 \%)$ & $33(30 \%)$ & $17(15.45 \%)$ \\
\hline 4th & $3(2.72 \%)$ & $26(23.63 \%)$ & $11(10 \%)$ & $44(40 \%)$ & $26(23.63 \%)$ \\
\hline $\begin{array}{c}\text { Least } \\
\text { important }\end{array}$ & 0 $(0 \%)$ & $33(30 \%)$ & $4(3.63 \%)$ & $24(21.81 \%)$ & $49(44.54 \%)$ \\
\hline
\end{tabular}

\section{8- Who do you think students hear from the most when making an important decision?}

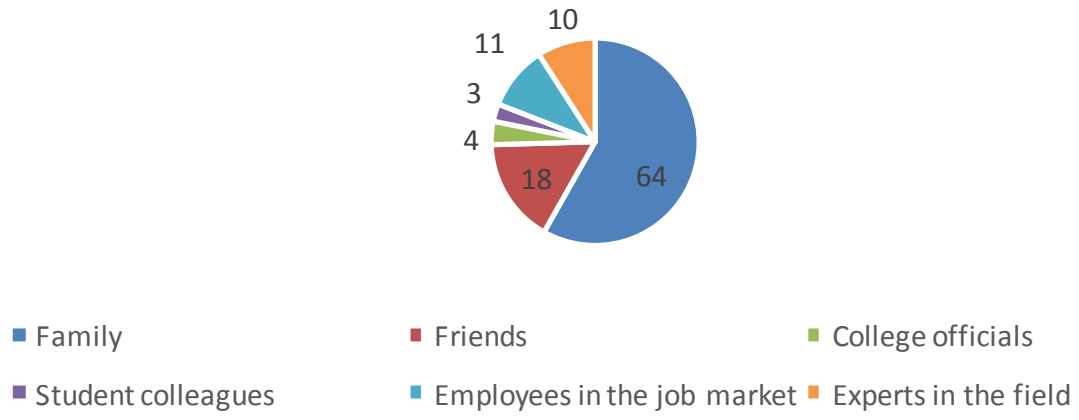

Figure 4: Student main body of reference

Aim of the question: to get an understanding of who students resort to or seek help from when facing an important decision

Figure 4 showed us that $58 \%$ of students depended on their families and $16 \%$ consulted their friends the most as opposed to $10 \%$ \& $9 \%$ who referred to employees in the job market and experts of the field, respectively. This left $4 \%$ who asked college officials and $3 \%$ who conferred with fellow colleagues.

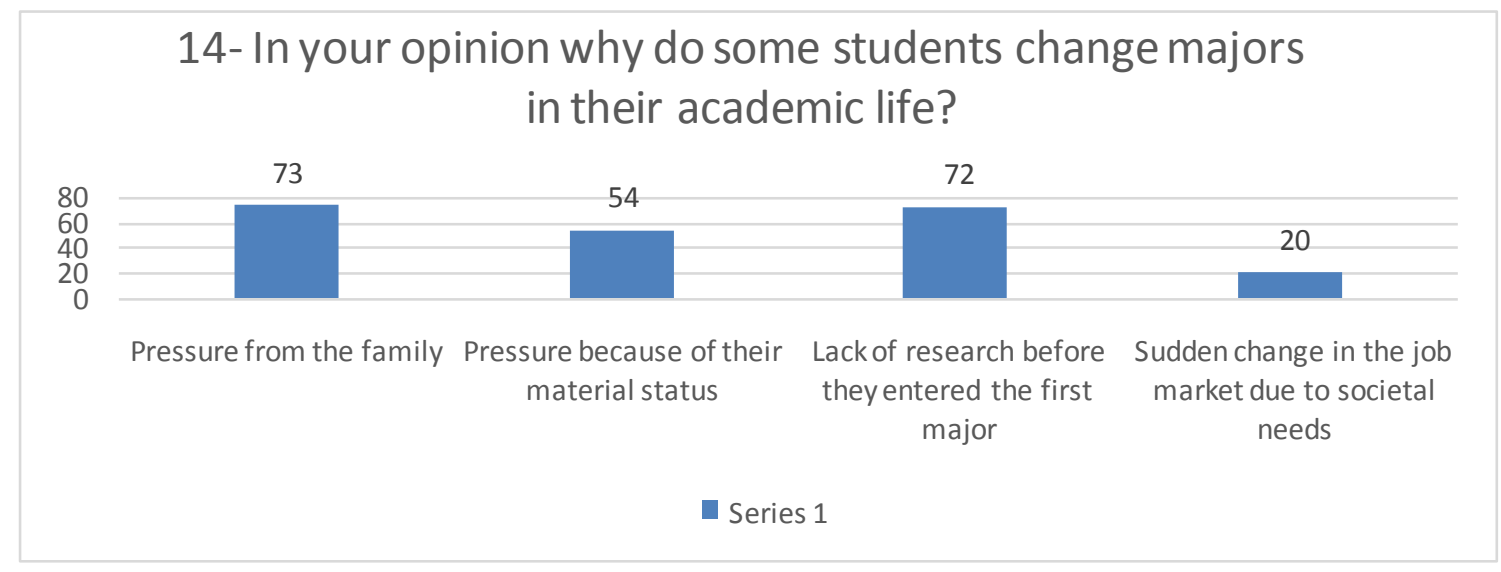

Figure 4: The main factors that affect students' decision

Aim of the question: to see if the important students' decisions can be affected by pressure considered in line with the thesis of the study and to draw a comparison with thesis negative factors

According to Figure 5 nearly $67 \%$ of respondents felt that family pressure was a driving factor in students changing majors, while nearly $66 \%$ chose lack of research on the students' part. Other than that, almost half of respondents (49\%) chose monetary and economic pressure as a driving factor for student field of study change. Meanwhile sudden change of societal and market needs only drew $18 \%$ of the respondent's responses. 
The third research question was as follows:

\section{RQ3: How does the outside pressure affect Saudi students' performance and passion for learning?}

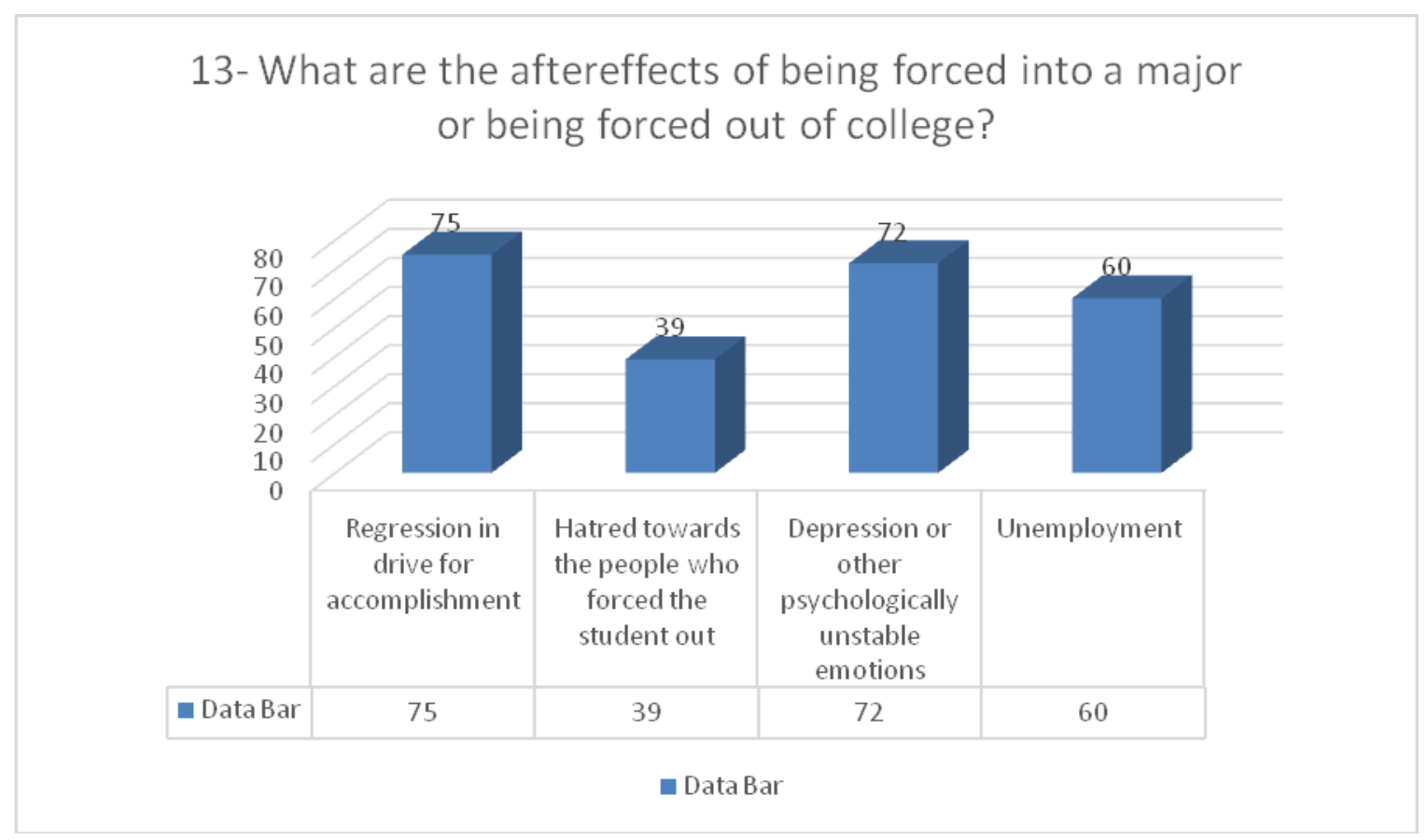

Figure 5: What is the main effect of pressure on students?

The two most chosen items were mental issues which were regression in the students drive for accomplishment and depression or other psychologically unstable emotions. These two choices garnered $68 \%$ and $65 \%$ of responses, respectively. The only physical effect in the survey was unemployment and it got $54 \%$ of the respondents' responses, while strong emotional effects like hatred got only $35 \%$.

\section{Discussion:}

This study aimed to find the outside pressure that affects Saudi students and their decisions. The major results of each research question are as follows:

RQ1- The vast majority of respondents site monetary reasons and family and societal acceptance as three of their top four bases when making an important career step [figure 1]. And almost $80 \%$ of the respondents agree with the sentiment that society affects the scope of available jobs. Moreover, $75 \%$ of respondents states that students make choices based on the opinions of others [figure 2], and 55\% chooses the family as the first reference for students when making an important decision as opposed to a measly $10 \%$ who chooses experts of the matter as the main fallback point [figure 4].

RQ2- The survey data raises an overall agreement with the survey hypothesis that students are affected by outside factors. As far as the decisions that are affected by these factors go, the respondents choose entering college and choosing their major as the two most important decisions students must make [figure 3]. When asked about why some students change their majors the answers are split between monetary reasons, family pressure and lack of research on the students' part with lack of research having a slight edge [figure 5]. However, when asked to organize these reasons based on their prevalence respondents lean more towards family pressure.

RQ3- When the survey examines the effects the pressure has on students, the main results are disregard in the outcome of the students' academic accomplishment and lack of creativity as well as depression and other psychological effects [figure 6].

Regarding RQ1, the results in Figure 1 above indicate that the most chosen basis of career or field of study is how lucrative it is. When seen alone, it seems merely a desire as opposed to being a pressure. However, when connected with items $1 \& 2$ of the survey (See appendix B), we can see that a surprisingly large number of students feel pressured by their monetary status in correlation to their families, perhaps feeling a responsibility to provide and support their families. 
Thus, it seems that economic status rarely pressures students on its own. In Figure 6 we can see that the leading reason why students change majors is pressure from the family. This is further reinforcing the notion that monetary status is not a strong enough pressure on the student to cause severe change in choice, however the results in items 3 \& 4 (Figure 2) show an overwhelming agreement with the effects of society and the family on the student choices.

In Figure 1 the second most chosen basis of major or job was that the field is respected by society. Societal stigmas limit students to only certain "acceptable" choices and this makes societal self-reliance difficult since it limits the potential for workers and students' versatility and as the results of RQ3 show, it limits the bounds of their creativity. This idea of monetary reasons going hand in hand with societal reasons or in the case of the Saudi demographic the family as well is not a new idea or result.

When it comes to RQ2, according to the data in Figure 3 the most important decisions are entering college and choosing majors. As we can gather from the results of item 1, 2, 7 and most importantly 14 (appendix B), societal stigmas affect the scope of available jobs. This affects the Kingdom in such a crucial time where the Kingdom is aiming for a change to a more self-reliant economy. To accomplish this, it will need every specialization and if students keep steering into "accepted" fields, this can cause severe consequences that include market saturation and relying on foreign contractors which can prove expensive.

The previously mentioned items reinforce the results that family affects students' choices as well (See figure 2). It could be concluded that there is a possibility that family pride in students can contribute to limiting their creativity and the variation of fields available. To be proud of their kids' accomplishment, society must be accepting of their choice and families tend to compare their kids' accomplishment with societies status and the accomplishment of others. So, if society respects the field of medicine, there will be extra emphasis on the kids joining and accomplishing in these highly competitive environments. According to an article published by (Hazari, 2014) an increasing amount of research works gives convincing proof that parent behaviors and attitudes affect their kids' emotional responses. Experiential researches from Johns Hopkins University tell that behaviors in which fathers and mothers get involved and advocate for their kids' instruction rely upon parents' understanding of academic achievement (Young, 2018).

There is no doubt that pressure affects students' performance but how do different kinds of pressure affect performance? According to Finkelstein et al (2007) in a school work of the role of Socioeconomic Status (SES) on Adolescent Stress, investigators discover that undergraduates with professionally educated parents practice lesser stages of pressure and advanced stages of hopefulness. Advanced pressure stages can manifest in undergraduates as social difficulties that hinder classroom growth. Lesser SES students -whether they are under stress to work and attend university at the same time to help out at home or are otherwise passionately taxed by their family status- can have trouble with performing under stress, memorization or otherwise being the superlative they can be in the classroom.

The effects of pressure are further reinforced by the results of items $14 \& 15$ (See appendix B) where over 50\% of respondents state that family pressure and monetary status are among the most prevalent reasons why students change majors. When viewing those results, we can make a correlation with what was established in previously concerning the effects on performance. The second most chosen response in item 10 (See appendix B) is lack of creativity regarding the question about challenges student face when pressured into decisions. This is reinforced by Clark and Zimmerman (1988) in their study where they say"CCreativity is thought to be a product of the family environment."

\section{Conclusion}

This study was about the pressure Saudi students face and how it affects their decision-making and it aims at finding the types that are most prevalent and how they affect the students. Its importance stems from the fact that the Kingdom is in a stage of change and development and it needs its young manpower firing on all cylinders and we must give them the environment that ensures that they perform on the highest levels.

Heading into this research there are some pre-conceived notions about the pressure students face like family, economic status, etc. and this study reinforces these notions and gave a better idea of how common and affecting they are. The results of this study mostly agree with prior studies and below are three examples.

Kids from lesser SES families are approximately double as probable as those from high-SES families to show learningrelated behavior difficulties. A mother's SES is also connected to her kid's distraction, disregard and absence of collaboration in school (Morgan et al., 2009). In 2014, the high school failure degree among persons 16-24 years old is the uppermost in low-income families (11.6\%) as compared to high-income families (2.8\%) (Morgan, 2009).

The achievement degree of low-income students in technology, science, mathematics and engineering disciplines is much lesser than that of students who do not come from understated backgrounds (Doerschuk et al., 2016). 
The results have risen some interesting thought for further study like what is the link between a certain pressure (i.e. What does society have to do with the family environment and their hopes and desires for their children?; How does socioeconomic status affect the ambition of students?; To what degree are people bound to follow the path laid out to them by society, family or monetary status?). These issues might have been tackled before in other demographics, but how they have been covered and remedied in the Saudi, Arabic or Islamic context remains a wildly non-tackled topic.

In some countries abroad campuses have a team of psychologists on hand in colleges that act like academic advisors, but they are concerned with life matters which can offer students a means to seek advice and deflate some of their troubles. This is an unexplored avenue in the Kingdom's universities and even the neighboring countries. So, it is a recommendation worth considering. Another recommendation for the universities is that they prepare and execute activities, galas and field days that invite families to see what the university has to offer. This can help expand the family's perception of the opportunities their kids may get regardless of the field's popularity.

This study is affected by the timeframe in which it is made in, namely there are troubles in getting the results since there is an influx of studies and surveys being distributed and there are examinations and tests that are occupying the students' minds. In turn this affects the team of students in charge of this study where there may have been weak questions in the survey and items that are repetitious in nature or merit.

\section{References}

American College Health Association-National College Health Assessment. (2019). [Online] Available: https://www.acha.org/NCHA/About_ACHA_NCHA/Overview/NCHA/About/About_NCHA.aspx?hkey=75ea a64f-e82c-4cfd-a19c-4e3f9bf126ee

Clark, A. \& Zimmerman, E. (1988). Views of Self, Family Background, and School: Interviews with Artistically Talented Students. Gifted Child Quarterly, 32(4): 340-346. [Online] Available: https://journals.sagepub.com/doi/pdf/10.1177/001698628803200402

Doerschuk, P. et al (2016). Closing the Gaps and Filling the STEM Pipeline: A Multidisciplinary Approach. Journal of Science Education and Technology, 25(4): 682-695.

Finkelstein, D. et al (2007). Socioeconomic Differences in Adolescent Stress: The Role of Psychological Resources. The Journal of Adolescent Health. 40(2): 127-134. [Online] Available: https://www.ncbi.nlm.nih.gov/pmc/articles/PMC1847603/

Hazari, A. (2014). The Biggest Stress for Students: Parental Pressure. Generation 40S. [Online] Available: https://generation40s.wordpress.com/2014/01/14/the-biggest-stress-for-students-parental-pressure/

Kaur, S. (2013). Academic Pressure. Sutter Health, Pola Alto Medical Foundation. [Online] Available: http://www.pamf.org/teen/life/stress/academicpressure.html

Locke, B. (2017). Annual Report. Center for Collegiate Mental Health. Penn State University, 501 Student Health Center, University Park, PA 16802.

Morgan, P. et al (2009). Risk Factors for Learning-Related Behavior Problems at 24 Months of Age: Population-Based Estimates. Journal of Abnormal Child Psychology, 37(3): 401-13.

Novotney, A. (2014). Students under Pressure. American Psychological Association. 45(8): [Online] Available: http://www.apa.org/monitor/2014/09/cover-pressure.aspx

Nooreddin, M. \&Mubarakah, K. (2016). The role of Parents in Determining the Future of Their Children at the Level of Guidance. KasdiMerbah University. [Online] Available: https://dspace.univ-ouargla.dz/jspui/bitstream/123456789/10577/1/S2407.pdf

Pedrelli, P. et al (2015). College Students: Mental Health Problems and Treatment Considerations. Academy Psychiatry. 39(5): 503-511. [Online] Available: https://www.ncbi.nlm.nih.gov/pmc/articles/PMC4527955/

Polavieja, J. \& Platt, L. (2014). Nurse or Mechanic? The Role of Parental Socialization and Children's Personality in the Formation of Sex-Typed Occupational Aspirations. Social Forces, 93(1), 31-61. [Online] Available: https://core.ac.uk/download/pdf/29407174.pdf

Porcelli1, A. \& Delgado, M. (2017). Stress and Decision Making: Effects on Valuation, Learning, and Risk-taking. Current Opinion in Behavioral Sciences, 14: 33-39.

Reilly, K. (2018). Record Numbers of College Students Are Seeking Treatment for Depression and Anxiety. [Online] Available: http://time.com/5190291/anxiety-depression-college-university-students/

Tolosa C. et al (2018). Factors Affecting in Choosing Bachelor of science. Academia Premium Future. [Online] Available: https://storify.com/jessieagarwal/challengesstudents-face-when-choosing-a-career

Young, S. (2018). The Effect of Socioeconomic Status on Student Achievement. [Online] Available: https://classroom.synonym.com/effect-socioeconomic-status-student-achievement-16898.html 